\title{
Plan Management for Production Schedule in Aviation Manufacturing Enterprises
}

\author{
Wang Qingjun \\ Economics and Management Institute \\ Shenyang Aerospace University \\ Shenyang City, China \\ 32582669@qq.com
}

\author{
Wu Jingtai \\ Economics and Management Institute \\ Shenyang Aerospace University \\ Shenyang City, China
}

\begin{abstract}
Along with the technological advances and development of the society, China's aviation industry is also developing. How to optimize the production schedule in aviation manufacturing enterprises has become the primary problem for developing aviation projects. This paper analyzes the current condition of the production schedule management in modern aviation manufacturing enterprises and come up with relevant solutions to solve the existing issues.
\end{abstract}

Keywords-Aviation manufacturing enterprises; Production schedule;

\section{THE CONDITION FOR PRODUCTION SCHEDULE MANAGEMENT IN MODERN AVIATION MANUFACTURING ENTERPRISES}

Along with the technological advances and development of the society, China's aviation industry is also developing and aviation enterprises face more and more pressure in terms of manufacturing task. Therefore, it is urgent to optimize the aviation manufacturing production schedule. This paper aims to research on a certain aviation manufacturing enterprise, which always adopts assembly pulling production model and JIT timely production management model.

The assembly pulling model refers to the condition that school-level factories accept tasks and divides the tasks into annual production plan and then allocates the tasks into various departments, which are responsible to divide the final assembly and dispensing. What's more, the annual production plan as well as the final assembly and dispensing should be carried out based on the actual situation so as to make an assembly pulling seasonal plan. Furthermore, school-level factories divide the seasonal plans into monthly key plans and allocate these plans to departments, which are responsible to divide the final assembly and dispensing tasks. Besides, the monthly key plans carried out by school-level factories as well as the final assembly and dispensing divided by departments should be implemented based on actual condition and the requirement of assembly factories.

In aviation production, we have to differently deal with the products in each production stages. The point system organizations are responsible to control and manage the allocated production projects; relevant schedules should be carried out based on the manufacturing technique; the manufacturing technique include the preparatory work before production, full system production planning and subsystem production planning etc.

At present, there are three production management methods for aviation enterprises:

Firstly, in aviation enterprise production, manufacturing enterprises should carry out detailed self-examination on their units, production schedule. After the examination, they should make reporting materials. The reporting material of underling units should include the production implementation process, the production condition, existing problems and solutions etc. What's more, we should have a good knowledge of the production process so as to carry out a report. While underling units report information, they have to deliver detailed materials.

Secondly, while carrying out production management, aviation enterprises should carry out on-the-spot investigation on manufacturing units which can help enterprises have a more detailed understanding on the production schedule to carry out supervision and management. At the same time, the on-the-spot investigation can guarantee the authenticity of production schedule.

Thirdly, aviation manufacturing enterprises should regularly hold meetings to deal with the production schedule. Participants can be relevant personnel and the meeting should be hold regularly to discuss about the production condition, existing problems and solutions etc. What's more, concerning the frequent problems occurring in the production process, we have to come up with relevant solutions. The holding meeting can help enterprises to have a more detailed understanding on the manufacturing units.

The underling units reporting, on-the-spot investigation, meetings about production schedule adopted in the course of production management will be helpful to the production. At the same time, these three methods can also help enterprises to supervise on the production schedule of the manufacturing units. 


\section{PROBLEMS OCCURRING IN THE COURSE OF PRODUCTION MANAGEMENT OF AVIATION ENTERPRISES}

Even though the aviation manufacturing enterprises develop quickly, we also find out that there are problems caused by the demerits of the assembly pulling production management model:

Firstly, the production planning in aviation manufacturing enterprises is defective without detailed production planning and scientific analysis in the course of implementation, which is greatly affected by subjective factors. The biggest problem is that the production planning lacks details. At present, the production planning in aviation manufacturing enterprises is mainly carried out based on the customer order quantity as well as the delivery time, lacking the explanation on the products quantity during each period. Even though, advances and optimizations have been conducted in terms of production planning, the result is ineffective and there is still no detailed explanation on the production management planning establishment.

Secondly, the aviation manufacturing enterprises' assembly pulling production management does not introduce the annual implementation plan into practice. At present, the main production pan focuses on the monthly plan scheduling supplemented by annual plans. In real production of aviation manufacturing enterprises, the emergence of any unexpected situations will affect the production process. In adjustment period, the monthly plan scheduling determines the production process and therefore the annual plan production is inconsistent with the actual implementation.

Thirdly, the overall products production plans are assigned to subsystems, which determine the production schedule of the production organization structure of subsystems. However, in actual production, different subsystems have different production schedule and parts of them have slow production speed which affect the overall speed and therefore such production planning have big defects.

Fourthly, there is a dazzling array of factors that will affect the production manufacturing process in actual production. According to investigation, there are differences between actual production and the production plan because there will be countless of unexpected situations in actual production which all affect the production schedule, leading to the condition that the production schedule of subsystems are different. Under such condition, the newly-made plan based on pulling model is not suitable.

\section{ANALYSIS ON THE CAUSES OCCURRING IN THE COURSE OF PRODUCTION MANAGEMENT}

\section{A. The causes of production managers}

An outstanding enterprise cannot be separated from excellent mangers and if there are problems occurring in the production schedule, managers cannot weasel out of responsibility. In investigation, we find out that parts of managers have a shallow knowledge of the management, think unilaterally, cannot take the big picture into consideration and do not take actual factors which will affect the production cycle into consideration. They only make plans based on the experience and assumption to manage the production schedule. Excellent managers can ignite the enthusiasm of employees in the course of production and accelerate the production schedule while parts of the managers do just the opposite.

\section{B. Influences of products returning to factories}

The technology status and the design technique of parts of products may change after leaving factory, which should be returned to the factory. However, these products are not included in the monthly and annual plan. Therefore, these products will affect the original production schedule. However, aviation enterprises have limited conditions in terms of production, research and management so while solving the return factory repairing, the production schedule may change.

\section{Influences of products purchasing}

The products purchasing problem is one of the biggest issues affecting the production schedule. Firstly, if you want to order a certain product you have to investigate and will cost much time on products purchasing, contract signing etc. Therefore, there may be a series of influential factors to make a clear contract. For example, national macro-economic situation, different order requests and quantities, customer budgetary resources, payment method and price disputes etc.

\section{Causes of aviation manufacturing enterprises}

Comparing to other industries, aviation manufacturing enterprises have large scale, complicated environment, and the overall products planning can be assigned to the subsystems with various production projects, distinct differences and can be manufactured in parallel. Therefore, we can see that various factors will affect the production schedule. For example, improper coordination among subsystems may cause difficulties in implementation, which thereby affect the production schedule.

\section{E. Problems of the original materials}

In actual production of aviation manufacturing enterprises, the original material supply is also a significant problem affecting the production schedule. Factories may not timely provide materials or cannot provide enough materials. Sometimes, there may be quality problems in terms of materials, which shall affect the production schedule. However, we cannot find out relevant solutions to solve these problems.

\section{F. Problems of underling units}

In recent years, aviation manufacturing enterprises are constantly improving and underling units are also developing with sound mechanisms to easily deal with the requirement put forward in the course of production. However, there are still problems.

The development of aviation industry will increase the production tasks of aviation manufacturing enterprises, which also improve the difficulties of production because customers ask higher requirement on the overall quality, asking underling units to coordinate and communicate properly. However, the coordination among underlying units has demerits with unclear partnerships, which severely restrict the production schedule. 


\section{COUNTERMEASURES TO DEAL WITH THE PRODUCTION SCHEDULE MANAGEMENT}

\section{A. Innovate the production plan of aviation manufacturing enterprises}

Even though, the aviation manufacturing enterprises develop rapidly in recent years, there are various demerits in terms of production management and schedule. Therefore, we have to innovate and reform the production plan. In terms of reform and innovation, we have to adopt the work breakdown structure with reasonable structures based on the principles of internal structure and production order as well as clear production plan. While preparing the production plan, we can divide the production system into full system structure, dynamic structure, guidance control system, fuse-warhead system, and catching command transmission system. What's more, the full system can be decomposed into components and accessories among which the production structure tree is responsible to decompose the aviation products. The advantage of decomposing work structure is that it can divide work based on requirement, which can also decompose entire work into structures and small units to create mutual effects.

\section{B. Opinions to optimize the production plan and schedule}

Aviation manufacturing enterprises have various factors, including work staffs, machine equipment, building materials, production methods, production links, production testing etc, which make the aviation manufacturing enterprises complicated and also affect the production schedule. To accelerate the production speed, we have to advance the production factors, including key work stations, equipment and products so as to reduce the production risk and regulate safeguard system; enterprises should also supplement the sectors and determine short boards to finally determine the implementation plan so as to make the production plan become scientific to accelerate the production schedule; besides, enterprises should also carry out special topic, discussing about the product quality, technology, supply, short boards etc and then analyze and explore the occurring problems with relevant solutions. Finally, enterprises should apply solutions to actual production sector and observe the comparison.

\section{Methods to optimize and reform the production schedule management}

\section{1) Enterprises should strengthen self-awareness}

Enterprises should strengthen self-awareness to correctly judge the production capacity based on production task and production process so as to have a good knowledge of the demerits to make it easy to reform and optimize.

In production, aviation manufacturing enterprises assign the tasks to underling units and decompose the overall object in recent years to the object in one year so as to decompose month plans and carry out detailed production management on underling units.

Enterprises should also compare the assigned tasks with the production plan by understanding the condition of the underling unit condition. Then, based on the understanding of assigned plan and moderate outsourcing, enterprises can have a good knowledge of its production capacity. Concerning less important issues, enterprises should not pay attention to. Yet, concerning important issues and short boards, enterprises cannot ignore so as to assign the work process to underling units so as to find out relevant solutions. In order to prevent problems that may occur in the key equipments and bottleneck sector which will affect the production schedule enterprises should carry out more configuration tests.

2) Improve safeguard system

Enterprises should take product production as the core to reduce the production risks and develop relevant safeguard system. In order to improve the comprehensive support capability and production capacity, enterprises have to properly arrange resources. In order to prevent the unexpected issues, enterprises should back up key equipment and bottle neck equipment data so as to reduce the production risk and improve production assurance.

3) Strengthen the purchasing management of original materials

The biggest feature in aviation manufacturing enterprises is to ask the help of outsource to purchase products. Therefore, enterprises should manage the process. To begin with, enterprises should purchase proper products based on the annual production plan and quantity needs. While carrying out purchasing, enterprises have to purchase based on the type, and plan. What's more, after purchasing, enterprises should analyze the products and focus on the products based on the bottleneck so as to find out relevant solutions; besides, enterprises should also supervise the production schedule of the supplier, asking the supplier to complete products within scheduled time and carry out analysis on the bottleneck products with solutions; moreover, leaders should also carry out on-the-spot investigation and organize the outsource to pay a visit for investigation so as to guarantee the production schedule.

4) Optimize product manufacturing technique

In production, the most important issue is the manufacturing technique. Even though, parts of products are completed the returning will also affect the production schedule. Therefore, production optimization is of significant importance. Excellent technique asks serve requirement on the production, which needs enough preparation to pay attention to the equipment testing, prepare production and correct production plan, examine products so as to ensure that the plan can have effective affect on the actual operation.

5) Carryout statistic analysis on the quality

The production process of aviation manufacturing is complicated and lots of quality problems may occur. Therefore, we have to conduct statistic analysis on the quality problems and find out relevant solutions for these problems. If there should be same problems, enterprises can timely solve the problems which can help to accelerate the production schedule.

\section{ACKNOWLEDGMENT}

The work is supported by the Aviation Foundation (2013ZG54034).

\section{REFERENCES}

[1] National Defense Technology Factory Commission. Development of 
Civil Aircraft.2000 - 11

[2] Ministry of Science and Technology. Overall Conceptual Scheme for Implementation of Informatization Engineering in the Manufacturing Industry.2002-04

[3] Wang Ke. Application of Lean Manufacturing and Manufacturing Execution System in the Aviation Manufacturing Enterprises [J]. Aeronautical Manufacturing Technology

[4] Liu Liu. Application of Lean Manufacturing in A Aviation Enterprises [D]. Suzhou University, 2014.
[5] Chen He. Go from Lean Manufacturing to Lean Enterprise [J].New Technology and New Process, 2013,10:103-108.

[6] Qi Changgui, LiU Zhenzhong,Wang Huanyu. Research on the internal supply chain management of aviation manufacturing enterprises [J]. Aeronautical Manufacturing Technology, 2012,6:68-72.

[7] Zhu Hongliang. Project progress management[M]. Beijing: Tsinghua University Press, 2002.3-6. 